\title{
Increased Antioxidant Activity, Despite Reduced Rosmarinic Acid Accumulation in Methanolic Extracts, of Spearmint (Mentha spicata L.) Plantlets Regenerated In Vitro
}

\author{
Dani Fadel $^{1}$, Spiridon Kintzios ${ }^{2, *}$, Athanasios S. Economou ${ }^{1}$, Georgia Moschopoulou ${ }^{2}$ and \\ Helen - Isis A. Constantinidou ${ }^{3}$ \\ ${ }^{I}$ Department of Horticulture, School of Agriculture, Aristotle University, Thessaloniki, Greece; ${ }^{2}$ Laboratory of Plant \\ Physiology, Faculty of Agricultural Biotechnology, Agricultural University of Athens, Athens, Greece; ${ }^{3}$ Department of \\ Crop Science, School of Agriculture, Aristotle University, Thessaloniki, Greece
}

\begin{abstract}
One hundred spearmint (Mentha spicata) plantlets were regenerated from apical shoot segments of ten fieldgrown donor plants. Although the accumulation of rosmarinic acid and total phenolics in vitro was almost half than in vivo, regenerants demonstrated a tenfold-higher hydrogen peroxide compared to the donor plants. This finding may have been associated with the increased activity of hydroxyphenylpyruvate reductase, a key enzyme of the phenolic biosynthetic pathway and the increased production of yet unidentified phenolic compounds in vitro. This process of in vitro culture associated with a reduction of rosmarinic acid and total phenolics and with an increase of the antioxidant capacity indicated the possible promotion of in vitro-specific biosynthetic pathways.
\end{abstract}

Keywords: Mentha spicata L., antioxidant activity, in vitro regeneration, phenolics, rosmarinic acid.

\section{INTRODUCTION}

Spearmint (Mentha spicata L., Lamiaceae) is a herbaceous perennial plant, which is worldwide cultivated for its leaves, containing essential oils (giving the characteristic minty aroma when crushed) and phenolic compounds with antioxidant properties [1]. Among them, rosmarinic acid, $\alpha$ O-caffeoyl-3,4-dihydroxyphenyllactic acid, is the most prominent antioxidant phenolic constituent of the Lamiaceae, Boraginaceae and Apiaceae families [2, 3], with a plethora of pharmaceutical properties. As a hybrid, spearmint is rarely propagated by seeds and as a consequence, is exclusively propagated by vegetative cuttings and micropropagation [4-6]. So far, the antioxidant activities of spearmint have been strictly associated with its rosmarinic acid content [7], while no study so far has reported the accumulation of rosmarinic acid, total phenolics and antioxidant properties of spearmint plantlets derived from in vitro cultures.

Therefore, the aim of the present study was to investigate the rosmarinic acid and total phenolic content of spearmint (Mentha spicata L.) plants regenerated in vitro, along with the antioxidant activity of their methanolic extracts.

\section{MATERIALS AND METHODS}

\section{Explant Preparation}

One hundred spearmint plantlets were regenerated in vitro from apical shoot segments of ten donor plants, following a modification of a previously described protocol [8].

\footnotetext{
*Address correspondence to this author at the Laboratory of Plant Physiology, Faculty of Agricultural Biotechnology, Agricultural University of Athens, 11855 Athens, Greece; Tel: +302105294292;

Fax: +302105294286; E-mail: skin@aua.gr
}

\section{Plantlet Regeneration}

For shoot formation, the nodal segments were placed vertically for four weeks in Murashige and Skoog (MS) medium containing $3 \%(\mathrm{w} / \mathrm{v})$ sucrose, $0.8 \%(\mathrm{w} / \mathrm{v})$ agar, $0.1 \%(\mathrm{w} / \mathrm{v})$ myoinositol and supplemented with $1 \mathrm{mg} / \mathrm{L} 1$-naphtalene acetic (NAA) and $9 \mathrm{mg} / \mathrm{L}$ 6-benzyladenine (BA). The $\mathrm{pH}$ was adjusted to 5.8. The in vitro cultures were subcultured two times four week intervals and were maintained in a walk-in growth room with a temperature of $24 \pm 2^{\circ} \mathrm{C}$ and light of 16 $\mathrm{h}$ daily from cool-white fluorescent lamps at a photosynthetic photon flux density of $80 \mu \mathrm{mol} \mathrm{m} \mathrm{m}^{-2}$.

At the end of the 12-week culture period, regenerated shoots were separated and individually transferred for four weeks to growth regulator-free MS medium for rooting. Rooted plantlets were subsequently transferred to pots containing soil and peat (1:1). In vitro 16 weeks old regenerated plantlets were subjected to further analysis.

\section{Determination of Total Phenolics and Rosmarinic Acid Concentration}

The determination of total phenolics concentration in the regenerated plantlets was performed as reported previously [8]. One hundred $\mu 1$ of each phenolic aliquot was aligned and a drop of pure rosmarinic acid for identification was spotted at $1 \mathrm{~cm}$ from the low edge of a TLC. The TLC was run in a system of $\mathrm{C}_{4} \mathrm{H}_{10} \mathrm{O}: \mathrm{CH}_{3} \mathrm{COOH}: \mathrm{H}_{2} \mathrm{O}$ (3:1:1). After UV identification, rosmarinic acid was isolated, collected and centrifuged at $13000 \mathrm{rpm}$ for $5 \mathrm{~min}$. The supernatant was collected and the total volume was adjusted to $500 \mu$ l. The concentration of rosmarinic acid was expressed in terms of mg RA equivalent / $\mathrm{g}$ fw at $333 \mathrm{~nm}$ on Ultraviolet-Visible (UV-VIS) and HPLC method was applied to methanolic extracts having 
the best 18 and the worst 10 rosmarinic acid contents and the correlation among data was studied [9].

\section{Hydrogen Peroxide and Key Enzymes Activity}

The estimation of hydrogen peroxide scavenging ability of phenolic extracts was done by replacement of titration method with simple titration using $\mathrm{NaS}_{2} \mathrm{O}_{3}$ [10]. The enzyme activity of L-phenylalanine ammonia lyase (PAL) and Hydroxyphenylpyruvate reductase (HPPR) in the plant phenolic biosynthetic pathway was estimated by measuring respectively the production of trans-cinnamic acid and hydroxyphenyllactic acid $[11,12]$. PAL catalyzes the oxidative desamination of phenylalanine, resulting into the formation of trans-cinnamic acid, while HPPR is responsible for the reduction of 4-dihydroxyphenylpyruvate to 4dihydroxyphenyllactate $[13,14]$.

\section{Statistical Analysis}

The treatments of each experiment were setup in a completely randomized design. The mean of two reading for each sample was registered. Statistical analysis was based on analysis of variance (ANOVA). Significant differences $(p<0.01)$ among the means were determined by Duncan's multiple range test.

\section{RESULTS AND DISCUSSIONS}

\section{Shoot Proliferation, Rooting and Plantlet Production}

Ten shoots from each nodal culture were obtained. At the end of the 12 week culture period, regenerated shoots rooted at essentially $99 \%$ were separated and individually transferred for four weeks to growth regulator-free MS medium. Rooted plantlets were subsequently transferred to pots containing soil and peat (1:1). In vitro regeneration and genetic transformation of Mentha species were also discussed [4]. Other reporters found that BA proved best for shoot regeneration and growth responses of some cultivars of nodal explant culture of Mentha arvensis [8].

\section{Total Phenolic and Rosmarinic Acid Concentration}

The average total phenolics and RA concentration in the field-grown donor spearmint plants was almost double than in regenerants (Fig. 1A, B). Considerable variation in total RA concentration was observed both in the donor plant and the regenerants. Consequently, regenerants were classified according to their RA content into high, medium and low RA accumulators (Table 1). Single factor ANOVA analysis was done (Table 2) and the differences between means were tested according to Duncan's multiple range test (Table 3).

A high positive correlation was observed between total phenolic and RA concentration in high and medium RA accumulators (Table 4). Although the process of in vitro culture was associated with a reduction of RA and total phenolics, the antioxidant capacity was increased, at least as far as the scavenging activity of hydrogen peroxide is concerned, thus indicating the possible promotion of in vitrospecific biosynthetic pathways.

On the contrary, the correlation in low RA accumulators was considerably lower. The correlation between HPLC and TLC results was highly significant $\left(\mathrm{r}^{2}=0.96\right)$. As far as in vitro variation of RA accumulation is concerned, there are only a few previous reports in the literature. For example, an observation of a medium-dependent variation of RA accumulation in Ocimum americanum in vitro shoot cultures was associated with induced genetic variation as revealed by RAPD (Random Amplification of Polymorphic DNA) analysis [9]. Similar studies were conducted and RA reached 178 $\mu \mathrm{g} / \mathrm{g}$ dry weight in Ocimum basilicum [8]. Other reporters have also reported 1.8\% RA equivalent from Salvia officinalis using ethanol-water mixtures [15].

\section{Hydrogen Peroxide and Key Enzymes Activity}

The $\mathrm{H}_{2} \mathrm{O}_{2}$-scavenging activity of the in vitro regenerants was ten times higher than that of the donor plants (Fig. 2). It is important to mention that assaying the inhibition of hydrogen peroxide-induced oxidation has been frequently used for evaluating the antioxidant properties of mint species, as reviewed previously [16]. It is possible that other antioxidant assays, such as the measurement of ferrous iron chelation and the 1,1-diphenyl-2-picryl-hydrazyl free radical scavenging activity provide different results regarding the antioxidant efficacy of spearmint extracts, as already reported previously [17]. Nevertheless, it has been also demonstrated that there exists a wide degree of variation between different phenolic compounds in their effectiveness as antioxidants
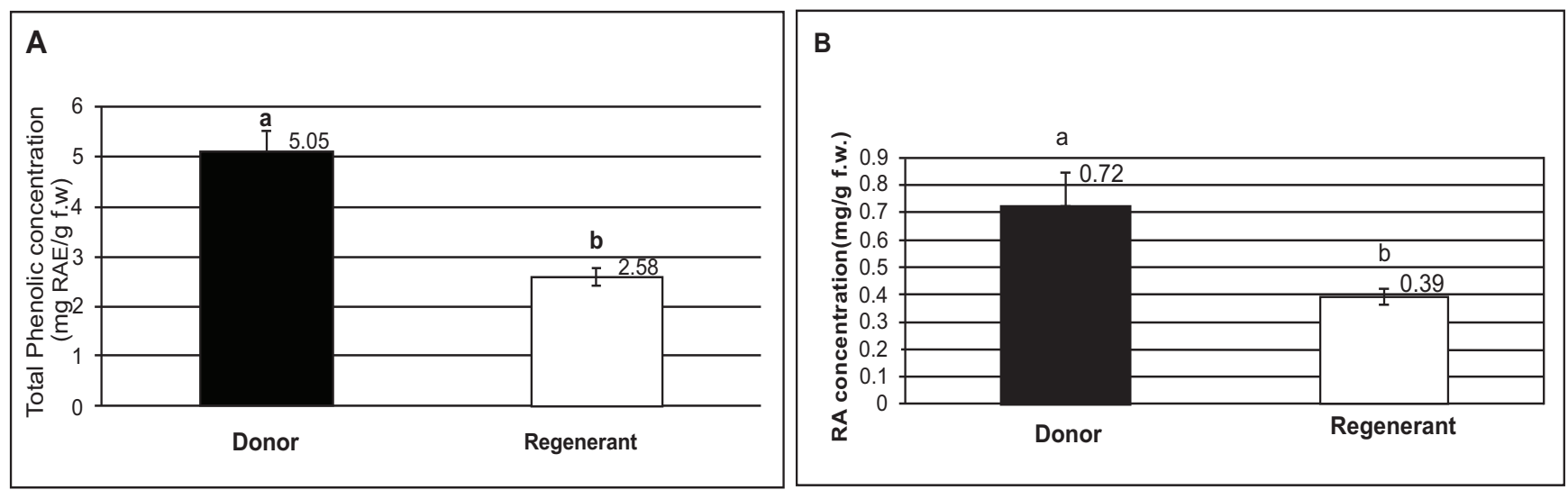

Fig. (1). Accumulation of total phenolics (A) and rosmarinic acid (B) in spearmint donor plants and regenerants. Vertical bars correspond to standard errors. Columns marked with different letters indicate statistically different values $(\mathrm{p}<0.01)$. 
Table 1. Phenolic and rosmarinic acid (RA) accumulation in spearmint donors and plantlets (mg/g fw \pm standard error). Numbers followed by different letters indicate statistically different values $(\mathbf{p}<0.01)$. Each Number is an Average of the number of plantlets.

\begin{tabular}{|c|c|c|c|}
\hline RA accumulators & Number of plantlets & Phenolics & Rosmarinic Acid \\
\hline \hline Donor & $\mathbf{1 0}$ & $\mathbf{5 . 0 5} \pm \mathbf{0 . 4 4 ^ { \mathrm { d } }}$ & $\mathbf{0 . 7 2} \pm \mathbf{0 . 4 1}{ }^{\mathrm{d}}$ \\
\hline Regenerant $^{*}$ & $\mathbf{1 0 0}$ & $\mathbf{2 . 5 8} \pm \mathbf{0 . 1 7 ^ { \mathrm { e } }}$ & $\mathbf{0 . 3 9} \pm \mathbf{0 . 0 3}{ }^{\mathrm{e}}$ \\
\hline High & 20 & $6.43 \pm 0.48^{\mathrm{a}}$ & $0.93 \pm 0.23^{\mathrm{a}}$ \\
\hline Medium & 60 & $2.36 \pm 0.43^{\mathrm{b}}$ & $0.32 \pm 0.14^{\mathrm{b}}$ \\
\hline Low & 20 & $0.56 \pm 0.07^{\mathrm{c}}$ & $0.05 \pm 0.04^{\mathrm{c}}$ \\
\hline
\end{tabular}

*High, medium and low RA accumulators together.

Table 2. Single factor ANOVA table of rosmarinic acid accumulator extracts (donor and regenerants).

\begin{tabular}{|c|c|c|c|c|c|c|}
\hline Between groups & 6.88 & 3 & 2.29 & 46.04 & $2.08 \mathrm{E}^{-12}$ & 4.37 \\
\hline Total & 8.68 & 39 & & & & \\
\hline
\end{tabular}

Table 3. Duncan's multiple range test table. Total phenolic accumulation in donor plants and regenerants (expressed as equivalent rosmarinic acid concentration $(\mathrm{mg} / \mathrm{g}$ fw \pm standard error).

\begin{tabular}{|c|c|c|c|c|}
\hline Phenolics & Donor & \multicolumn{3}{|c|}{ Regenerant } \\
\hline$L S R$ & 1.23 & 1.35 & 0.098 & 0.20 \\
\hline$S S R_{0.05}$ & 3.01 & & & \\
\hline
\end{tabular}

$[18,19]$. Although some researchers have reported a positive correlation between free radical-scavenging activity and total phenolic compounds in a number of plant species [20,21], it is possible that the individual phenolic constituents may exhibit different antioxidant properties. This hypothesis was further supported by the observed activities of PAL and HPPR in the plant phenolic biosynthetic pathway. Spearmint regenerants demonstrated a higher activity of both enzymes compared to the donor plants, indicating the possibility of an altered regulation of the phenolic biosynthetic pathway in vitro (Fig. 3). Although the activity of HPPR is closely related with rosmarinic acid accumulation, its overexpression may lead to the inhibition of rosmarinic acid biosynthesis [13]. This mechanism could provide an explanation for the reduction of the concentration of rosmarinic acid in the in vitro regenerants, while the observed changes in the phenolic biosynthetic pathway could be associated with the increased formation of constituents with $\mathrm{H}_{2} \mathrm{O}_{2}$-scavenging properties. In addition, leaves of non-acclimatized regenerants (such as those investigated in the present study) may possess a lessthan-complete photosynthetic apparatus; consequently, they may have a less-than-optimal oxidative pentose phosphate pathway, which in turn will have affected secondary metabolite synthesis in a negative way [22].

Table 4. Determination coefficient $\left(\mathrm{r}^{2}\right)$ between total phenolic and rosmarinic acid (RA) concentration in rosmarinic acid accumulators $(\mathbf{p}<\mathbf{0 . 0 1})$.

\begin{tabular}{|c|c|}
\hline Total Phenolic \& RA Concentration & R $^{2}$ value \\
\hline \hline Total Phenolic \& High RA accumulator & 0.91 \\
\hline Total Phenolic \& Medium RA accumulator & 0.94 \\
\hline Total Phenolic \& Low RA accumulator & 0.38 \\
\hline
\end{tabular}

\section{CONCLUSION}

In conclusion, the results of the present study suggest that in vitro culture may affect phenolic metabolic pathways in Mentha spicata. Further research in our group is aimed towards the identification of minor phenolic constituents formed in vitro as well as the molecular dissection of the respective biosynthetic pathways. 


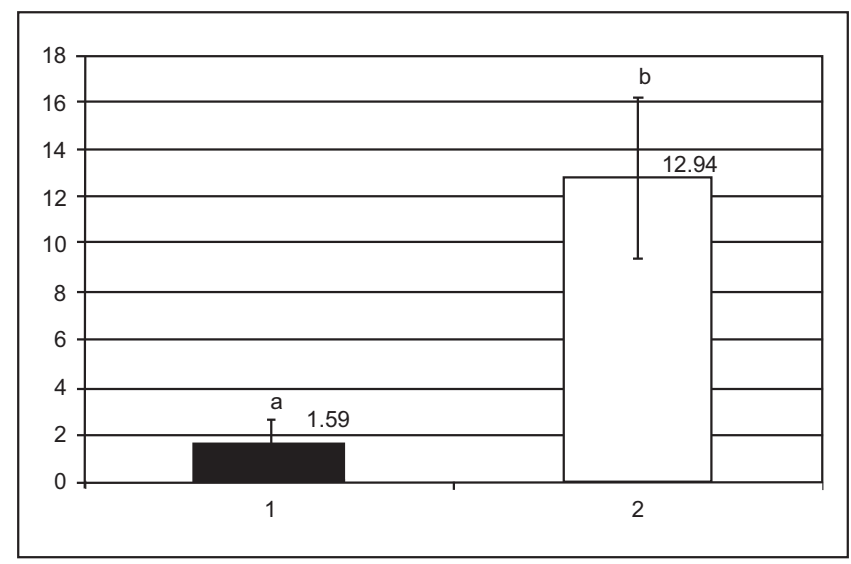

Fig. (2). Hydrogen peroxide-scavenging activity (expressed as equivalent ascorbic acid concentration) of spearmint donor plants and regenerants. Vertical bars correspond to standard errors. Columns marked with different letters indicate statistically different values $(\mathrm{p}<0.01)$.
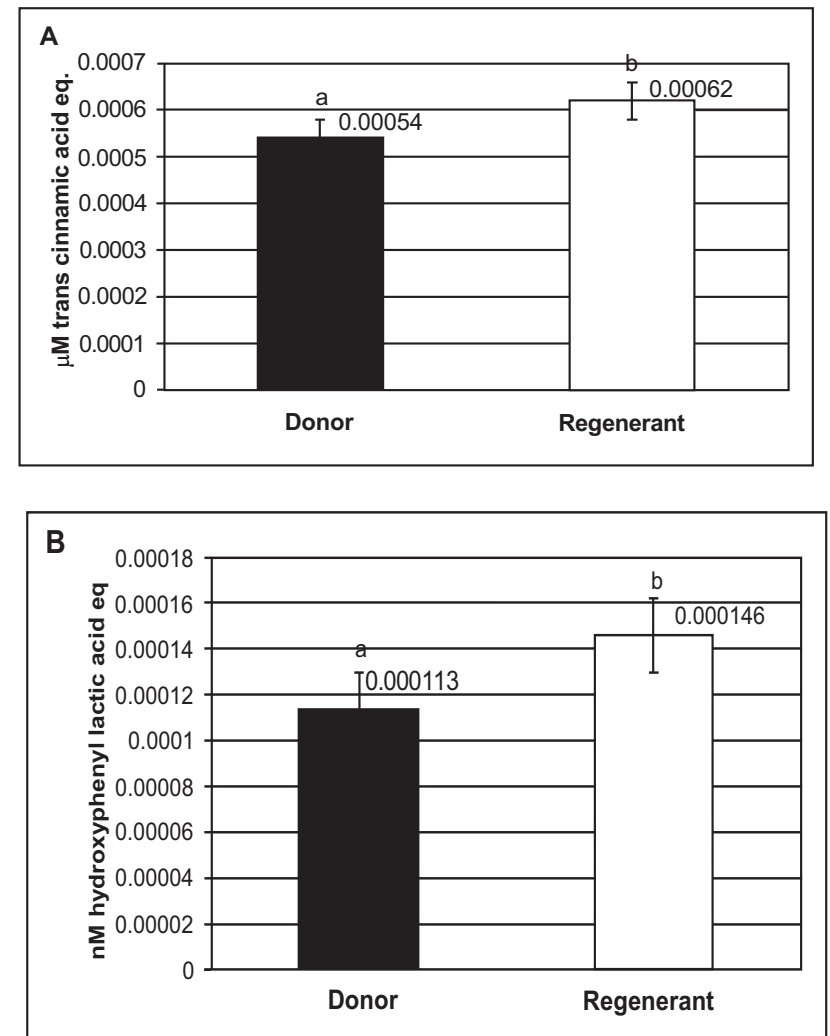

Fig. (3). L-phenylalanine ammonia lyase (PAL) activity (A) (expressed as trans-cinnamic acid concentration) and hydroxyphenylpyruvate reductase (HPPR) activity (B) (expressed as hydroxyphenyllactic acid concentration) of spearmint donor plants (black columns) and regenerants (black columns). Vertical bars correspond to standard errors. Columns marked with different letters indicate statistically different values $(\mathrm{p}<0.01)$.

\section{CONFLICT OF INTEREST}

The author(s) confirm that this article content has no conflicts of interest.

\section{ACKNOWLEDGEMENTS}

Dani Fadel acknowledges the support of the Greek National Scholarship Foundation.

\author{
ABBREVIATIONS \\ $\mathrm{BA}=6$-benzyladenine \\ HPPR = Hydroxyphenylpyruvate reductase (EC 1.1.1.237) \\ MS = Murashige and Skoog (1962) medium \\ NAA = 1-naphthaleneacetic acid \\ $\mathrm{PAL}=$ L-phenylalanine ammonia lyase (EC 4.1.3.5) \\ RA $=$ Rosmarinic acid \\ TLC = Thin Layer Chromatography
}

\section{REFERENCES}

[1] Kanatt SR, Chander R, Sharma A. Antioxidant potential of mint (Mentha spicata L.) in radiation-processed lamb meat. Food Chem 2007; 100: 451-8.

[2] Petersen M, Simmonds MSJ. Rosmarinic acid. Phytochemistry 2003; 62: 121-5.

[3] Petersen M, Abdullah Y, Benner J, et al. Evolution of rosmarinic acid biosynthesis. Phytochemistry 2009; 70: 1663-79.

[4] Shasany AK, Khanuja SPS, Dhawan S, Yadav U, Sharma S, Kumar S. High regenerative nature of Mentha arvensis internodes. J Biosci 1998; 23: 641-6.

[5] Li X, Niu X, Bressan RA, Weller SC, Hasegawa PM. Efficient plant regeneration of native spearmint (Mentha spicata $\mathrm{L}$.). In vitro Cell Div Biol - Plant 1999; 35: 333-8.

[6] Bhat S, Maheshwari P, Kumar S, Kumar A. Mentha species: In vitro regeneration and genetic transformation. Mol Biol Today 2002; 3: 11-23.

[7] Fletcher RS, Slimmon T, McAuley CY, Kott LS. Heat stress reduces the accumulation of rosmarinic acid and the total antioxidant capacity in spearmint (Mentha spicata L.). J Sci Food Agric 2005; 85: 2429-36.

[8] Kintzios S, Makri O, Panagiotopoulos Em, Scapeti M. In vitro rosmarinic acid accumulation in sweet basil (Ocimum basilicum L.). Biotech Lett 2003; 25: 405-8.

[9] Rady MR, Nazif NM. Rosmarinic acid content and RAPD analysis of in vitro regenerated basil (Ocimum americanum) plants. Fitoterapia 2005; 76: 525-33.

[10] Zheng W, Wang SY. Antioxidant activity and phenolic compounds in selected herbs. J Agric Food Chem 2001; 49: 5165-70.

[11] Petersen M, Alfermann AW. Two new enzymes of rosmarinic acid biosynthesis from cell cultures of Coleus blumei: hydroxyphenylpyruvate reductase and rosmarinic acid synthase. Z. Naturforsch 1988; 43c: 501-4.

[12] Reignault Ph, Cogan A, Muchembled J, Lounes-Hadj Sahraoui A, Durand R, Sancholle M. Trehalose induces resistance to powdery mildew in wheat. New Phytol 2001; 149: 519-29.

[13] Petersen M, Alfermann AW. Two new enzymes of rosmarinic acid biosynthesis from cell cultures of Coleus blumei: hydroxyphenylpyruvate reductase and rosmarinic acid synthase, Z. Naturforsch C 1988; 43: 501-4.

[14] Petersen M, Hausler E, Meinhard J, Karwatzki B, Gertlowski C. The biosynthetic of rosmarinic acid in suspension cultures of $\mathrm{Co}$ leus blumei Benth. Plant Cell Tiss Org Cult 1994; 38: 171-9.

[15] Durling NE, Catchpole OJ, Grey JB, et al. Extraction of phenolics and essential oil from dried sage (Salvia officinalis) using ethanolwater mixtures. Food Chem 2007; 101: 1417-24.

[16] Murcia MA, Egea I, Romojaro F, Parras P, Jiménez AM, Tome MM. Antioxidant evaluation in dessert spices compared with common food additives. Influence of irradiation procedure. J Agric Food Chem 2004; 52: 1872-81.

[17] Dorman HM, Kosar K, Kahlos Y, Hiltunen HR. Antioxidant properties and composition of aqueous extracts from Mentha species, hybrids, varieties, and cultivars. J Agric Food Chem 2003; 51: 4563-9. 
[18] Robards K, Prenzler P, Tucker G, Swatsitang P, Glover W. Phenolic compounds and their role in oxidative processes in fruits. Food Chem 1999; 66: 401-36.

[19] Kaur C, Kapoor HC. Antioxidant activity and total phenolic content of some Asian vegetables. Int J Food Sci Tech 2002; 37:15361 .

Received: September 18, 2013

Revised: December 11, 2013

Zheng W, Wang SY. Antioxidant activity and phenolic compounds in selected herbs. J Agric Food Chem 2001; 49: 5165-70.

[21] Wangensteem H, Samuelsen A, Malterud BKE. Antioxidant activity in extracts from coriander. Food Chem 2004; 88: 293-7.

[22] Lattanzio V, Cardinali A, Ruta C, et al. Relationship of secondary metabolism to growth in oregano (Origanum vulgare L.) shoot cultures under nutritional stress. Environ Exp Bot 2009; 65: 54-62.

(C) Fadel et al.; Licensee Bentham Open.

This is an open access article licensed under the terms of the Creative Commons Attribution Non-Commercial License (http://creativecommons.org/licenses/by-nc/3.0/) which permits unrestricted, non-commercial use, distribution and reproduction in any medium, provided the work is properly cited. 